Journal of Southeast Asian

\title{
Ethnicity, Gender, and the Education of Cambodian American Students in an Urban High School
}

Kimmie Tang

kimmietang@sbcglobal.net

Dennis Kao

University of Houston, dtkao@uh.edu

Part of the Education Commons

\section{Recommended Citation}

Tang, Kimmie and Kao, Dennis (2012) "Ethnicity, Gender, and the Education of Cambodian American Students in an Urban High School," Journal of Southeast Asian American Education and Advancement: Vol. 7 : Iss. 1, Article 3.

DOI: $10.7771 / 2153-8999.1045$

Available at: https://docs.lib.purdue.edu/jsaaea/vol7/iss1/3

This document has been made available through Purdue e-Pubs, a service of the Purdue University Libraries. Please contact epubs@purdue.edu for additional information.

This is an Open Access journal. This means that it uses a funding model that does not charge readers or their institutions for access. Readers may freely read, download, copy, distribute, print, search, or link to the full texts of articles. This journal is covered under the CC BY-NC-ND license. 


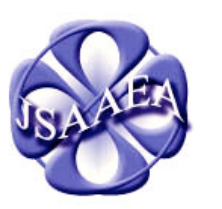

Volume 7 (2012)

\section{Journal of Southeast Asian American} Education \& Advancement

WWW.JSAAEA.org
A peer-reviewed scholarly journal published by the National Association for the Education \& Advancement of Cambodian, Laotian, and Vietnamese Americans (NAFEA)

\title{
Ethnicity, Gender, and the Education of Cambodian American Students in an Urban High School
}

\author{
Kimmie Tang \\ LoneStar LEND, \\ The University of Texas Health Science Center at Houston \\ Dennis Kao \\ University of Houston
}

\begin{abstract}
This paper explores the role of gender and ethnicity in the education of Cambodian American high school students. Using a qualitative approach, we interviewed ninth-grade Cambodian American students $(n=10)$, teachers $(n=4)$, and administrators $(\mathrm{n}=2)$ at a Southern California high school. The data revealed that Cambodian students were often mistaken for other Asian groups and due to stereotypes, expected to excel academically. Fearing that they would disappoint their teachers or be ridiculed by other students, they often remained silent about their academic struggles. Traditional values regarding gender and familial expectations also played prominent roles for both Cambodian boys and girls and their academic progress.
\end{abstract}

KEY WORDS: Cambodian American, high school, gender, ethnicity, education

\section{Introduction}

Asian Americans represent one of the fastest growing racial/ethnic groups in the United States, having nearly doubled in population since 1990 (P. M. Ong \& Leung, 2003). Over thirteen percent of the population in the state of California are now Asian Americans - making them the state's second largest minority group after Hispanics (Asian American Justice Center \& Asian Pacific American Legal Center, 2006). Despite tremendous population growth, Asian Americans remain largely neglected or "invisible" in the educational literature (Olsen, 1997). The Asian American population is commonly viewed as a homogeneous group and, consequently, there has been less attention on emerging ethnic subgroups, e.g. Cambodian Americans (Reyes, 2007). In

\footnotetext{
()

SOMERIGHISRESERVED Readers are free to copy, display, and distribute this article, as long as the work is attributed to the author(s) and the Journal of Southeast Asian American Education \& Advancement, it is distributed for noncommercial purposes only, and no alteration or transformation is made in the work. More details of this Creative Commons license are available at http://creativecommons.org/licenses/by-nc-nd/3.0/. All other uses must be approved by the author(s) or JSAAEA.
} 
2010, more than 276,000 Cambodians (alone or in combination with another race) were residing in the U.S., with 37\% of all Cambodians living in California, 10\% in Massachusetts, and 8\% in the state of Washington (United States Census Bureau, 2010).

While Asian Americans are commonly perceived to be highly educated, Cambodian Americans continue to face considerable educational challenges. Based on the 2000 Census, over half of the Cambodian Americans living in California (56\%) had less than a high school education, while only nine percent had earned a college degree. These disturbing patterns among Cambodian Americans contradict the notion of all Asian Americans being a "model minority," who have collectively adapted or integrated well into the U.S. society (Chou \& Feagin, 2008; Kao, 1995; Ng, Lee, \& Pak, 2007; Ngo \& Lee, 2007; Reyes, 2007; K. Yang, 2004). Unfortunately, the success story of high educational attainment - although it certainly applies to many individuals - has also led to stereotypes and overgeneralizations, where the relative success of some ethnic subgroups tends to overshadow the hardships and challenges faced by other ethnic subgroups (Kao, 1995; Olsen, 1997; P. Q. Yang, 2004).

Tremendous heterogeneity exists within the Asian American population, which is madeup of more than 45 distinct ethnic or cultural subgroups (Asian Pacific American Legal Center [APALC], 2004; P. M. Ong \& Leung, 2003). Significant differences also exist within each ethnic subgroup. For example, the status and well-being of an individual is often defined by his or her immigration experience, i.e. the conditions under which he or she came to the U.S. Many Asian Americans came to the U.S. as "voluntary" immigrants, who willingly came to seek better professional or educational opportunities, or to be reunified with family members (Ogbu \& Simons, 1998; Portes \& Rumbaut, 1996; Takaki, 1998). In contrast, Cambodian Americans (especially earlier generations) — as well as other refugee groups, e.g. Vietnamese, Hmong, Laotian, Burmese, etc. - are often referred to as "involuntary" immigrants, because they were forced to come to the U.S. due to fear of persecution in their home country. Many were forced to leave Cambodia to escape the persecution and mass genocide brought on by the Khmer Rouge in the 1970s and to seek refuge in another country. The 1980s represented the largest wave of Cambodians to the U.S., with about 114,000 being admitted as refugees (Chhim, 2003). For many of these first generation Cambodian Americans, the immigration process was a highly traumatic experience, making their adjustment that much more challenging. After two decades, many Cambodian Americans continue to face significant challenges and lag behind other groups in terms of socioeconomic status.

Since they were forced to immediately leave their homes, many Cambodian Americans continue to hold strong allegiances to Cambodia and also maintain their cultural and traditional values and beliefs (Takaki, 1998). In contrast, similar to other immigrant families, their children and grandchildren - who were either born in the U.S. or immigrated at a young age - may be more able or willing to adopt the mainstream culture and values (Zhou, 1997). As a result, like other immigrant and refugee groups, many families are struggling with an increasing cultural gap between the foreign-born parents and U.S.-born children and, Cambodian American children find themselves "straddling different worlds" (Zhou, 2001).

This type of intergenerational conflict can manifest in numerous ways, including differences in gender role expectations and the tension between family obligations vs. individual interests (Segal, 2002; Smith-Hefner, 1993; Takaki, 1998) - which in turn, can directly or indirectly influence the educational achievement of Cambodian American youth. For example, for many Southeast Asian populations, traditional values clearly define the roles and responsibilities along gender lines. On one hand, traditional norms that pressure girls to get 
married and start families may be a contributing factor to the relatively high drop-out rates found among Cambodian girls (Ngo \& Lee, 2007; Smith-Hefner, 1993). On the other hand, Southeast Asian parents may have higher educational or economic aspirations for their sons (Park, 2000), since males are expected "to assume the instrumental roles involving task accomplishment" (Segal, 2002, p. 188). These traditional norms may also help to explain the gender disparities in educational attainment. According to the 2000 Census, only one-third of Cambodian women aged 25 or older had a high school degree, compared to over half of their male counterparts. However, given the high poverty rates among the Cambodian population, boys may also be expected to work to support their families, which may distract them from focusing on their education (Ngo \& Lee, 2007). For example, in their study of Cambodian American college students, Chhuon, Hudley, Brenner, and Macias (2010) found that family obligation-a traditional value common in Cambodian and other Asian groups - was perceived to be both a motivating influence as well as a barrier to education.

Local schools must play a critical role in ensuring that these students are supported. However, more research is needed to better understand the educational challenges facing Cambodian American students-particularly in the school setting. This knowledge can help to inform school practices and interventions that would promote the educational opportunities for these students. Both classroom environment and teacher support have been found to be significantly related to academic engagement among Cambodian American high school students (Chhuon, Dosalmas, \& Rinthapol, 2010). Chhuon and Hudley (2010) further argue that teacher support can also help Cambodian American youth to develop more positive identities.

To our knowledge, no previous study has specifically focused on the role of gender and ethnicity in the education of Cambodian American high school students in the school setting. To address this gap, we conducted a study that addressed the following broad research questions:

- How does gender and ethnicity influence the perceptions or attitudes of the students towards school?

- Are the students aware of (and how do they perceive) the gender role expectations in their school and homes?

- How do the students perceive their own ethnicity? And how do they relate to students of other ethnicities, particularly other Asian ethnicities?

- How do parental expectations influence their attitudes towards school?

- Are the school and staff appropriately addressing the academic, social, and emotional needs of its Cambodian American students?

We conducted a qualitative study consisting of in-person interviews with students, teachers, and school administrators at a large urban high school in Southern California. In this paper, we explore how issues of gender and ethnicity may influence the academic experience of Cambodian American high school students and what is being done at the school level to address these issues. Based on the findings, we discuss the potential implications for future educational practice and research.

\section{How We Conducted The Study}

For this study, we employed a qualitative approach to delve more deeply into how gender and ethnicity may influence the academic experiences of Cambodian American students. To gain a 
fuller picture, we interviewed three groups of stakeholders at a large high school in Southern California, including the students themselves, their teachers, and school administrators. The study protocol was approved by the University of Southern California Institutional Review Board and the school district's research department. To gain access to the school, one of the coauthors (Tang) established a relationship with a staff person-who served as an invaluable gatekeeper regarding the school's inner workings, personnel, and other issues. We also met with school administrators to discuss the study's intent and to get their support.

\section{Study Site}

This study was conducted from September 2007 through January 2008 at a high school in one of California's largest districts, which also had a relatively high concentration of Cambodian American students. The school had roughly 4,300 students and over 200 staff personnel. Asian American students represented the largest racial/ethnic group in the school—with over a third of the student population (about 1,500) - followed by African Americans (25\%), Hispanics/Latinos $(25 \%)$, and Caucasians (12\%). Due to the lack of disaggregated data, it was not possible to determine the exact proportion of Cambodian American students. However, based on a 2008 school survey obtained from the district, roughly half of the Asian students identified Khmer as the language primarily spoken at home.

\section{Sample}

We purposively sampled administrators, teachers, and Cambodian American students to participate in our study. As shown in Table 1, our sample included two administrators, four teachers, and ten ninth-grade students (five boys and five girls). The four teachers were selected among those who taught ninth-grade English classes; students were primarily recruited from those classes. When we initially met with the school administrators, they suggested that we focus on these four classrooms due to the high number of Cambodian students. This turned out to be the case for two of the classrooms ( $n=14$ in Linda's class and $n=9$ in Nancy's class), but not necessarily so in the other classrooms ( $n=5$ in David's class). The fourth teacher, Barbara, was certain that she had Cambodian students in her class, but was not clear as to the exact number. The administrators also shared that the number of Cambodian students drastically dropped after each grade level.

To recruit students, we conducted informational sessions in the four classrooms and made announcements at several Cambodian student club meetings. Students who showed initial interest were provided information regarding the study and were sent home to ask their parents to sign informed consent forms - which were available in both English and Khmer. Since the interviews were conducted in English, students also needed to be English proficient. In two cases, the lead author spoke directly with the students' parents to provide further information and assurances regarding their child's participation in the study. Prior to the interviews, students were asked to complete a short questionnaire requesting demographic information, such as age, gender, birthplace, and number of years lived in the U.S. 
Table 1

Summary of Participant Characteristics

\begin{tabular}{|c|c|c|c|c|}
\hline Participants (pseudonyms) & Gender & Race & Tenure & \\
\hline \multicolumn{5}{|l|}{ Administrators $(n=2)$} \\
\hline Administrator 1 (Richard) & M & White & 12 & --- \\
\hline Administrator 2 (Charles) & M & Black & 2 & --- \\
\hline Teachers $(n=4)$ & & & & Class/gender breakdown: \\
\hline Teacher 1 (David) & M & White & 14 & $\begin{array}{l}37 \text { students ( } 22 \text { boys/ } 15 \text { girls }) \\
5 \text { Cambodian students } \\
\text { ( } 1 \text { boys } / 4 \text { girls })\end{array}$ \\
\hline Teacher 2 (Nancy) & $\mathrm{F}$ & White & 8 & $\begin{array}{l}33 \text { students ( } 14 \text { boys/19 girls) } \\
14 \text { Cambodian students } \\
\text { ( } 6 \text { boys / } 8 \text { girls) }\end{array}$ \\
\hline Teacher 3 (Linda) & $\mathrm{F}$ & Black & 8 & $\begin{array}{l}35 \text { students ( } 21 \text { boys/ } 14 \text { girls }) \\
9 \text { Cambodian students } \\
\text { ( } 7 \text { boys } / 2 \text { girls) }\end{array}$ \\
\hline Teacher 4 (Barbara) & $\mathrm{F}$ & White & 3 & $\begin{array}{l}35 \text { students ( } 19 \text { boys/16 girls) } \\
\text { Number of Cambodian } \\
\text { students not known }\end{array}$ \\
\hline $\begin{array}{l}\text { Students }(\boldsymbol{n}=\mathbf{1 0}) \\
\text { (Boys: James, John, } \\
\text { Robert, Michael, William; } \\
\text { Girls: Mary, Lisa, Susan, } \\
\text { Jennifer, Patty) }\end{array}$ & $\begin{array}{l}5 \text { boys } \\
5 \text { girls }\end{array}$ & Cambodian & $\begin{array}{l}14 \text { years } \\
\text { old; } 9 \text { th } \\
\text { grade }\end{array}$ & $\begin{array}{l}\text { Nativity and duration in the } \\
\text { U.S.: } \\
2 \text { U.S.-born ( } 1 \text { boy/ } 1 \text { girl) } \\
5 \text { foreign-born } / 5 \text { or more years } \\
\text { ( } 3 \text { boys } / 2 \text { girls) } \\
3 \text { foreign-born/less than } 5 \\
\text { years ( } 1 \text { boys } / 2 \text { girls) }\end{array}$ \\
\hline
\end{tabular}

\section{Data Collection}

The lead author (Tang) conducted in-person interviews with the administrators, teachers, and students, using three different semi-structured questionnaires specifically tailored for each group (see Table 2 for sample questions). The interviews consisted of open-ended questions that explored the perceptions regarding how Cambodian American students were faring, with a specific focus on issues related to gender and ethnicity. The students were also asked about their own experiences and perceptions as Cambodian Americans. The questionnaires were first piloted with an individual from each of the stakeholder groups and revised based on their feedback. In addition, the interviewer took notes during and after the interviews to highlight important issues that required future probing or clarification, as well as her own impressions and observations. Other individuals who worked at the school were informally interviewed to gather supplementary background information. These staff included school counselors, the school psychologist, security officers, coaches, and other paraprofessionals. We also specifically targeted the Cambodian staff members to gain more insight and context regarding the 
Journal of Southeast Asian American Education and Advancement, Vol. 7 [2012], Iss. 1, Art. 3

Tang \& Kao-Ethnicity, Gender, and the Education of Cambodian American Students

Cambodian American student population. The formal interviews were audio-recorded and professionally transcribed.

Table 2.

Sample Interview Questions by Stakeholder Group

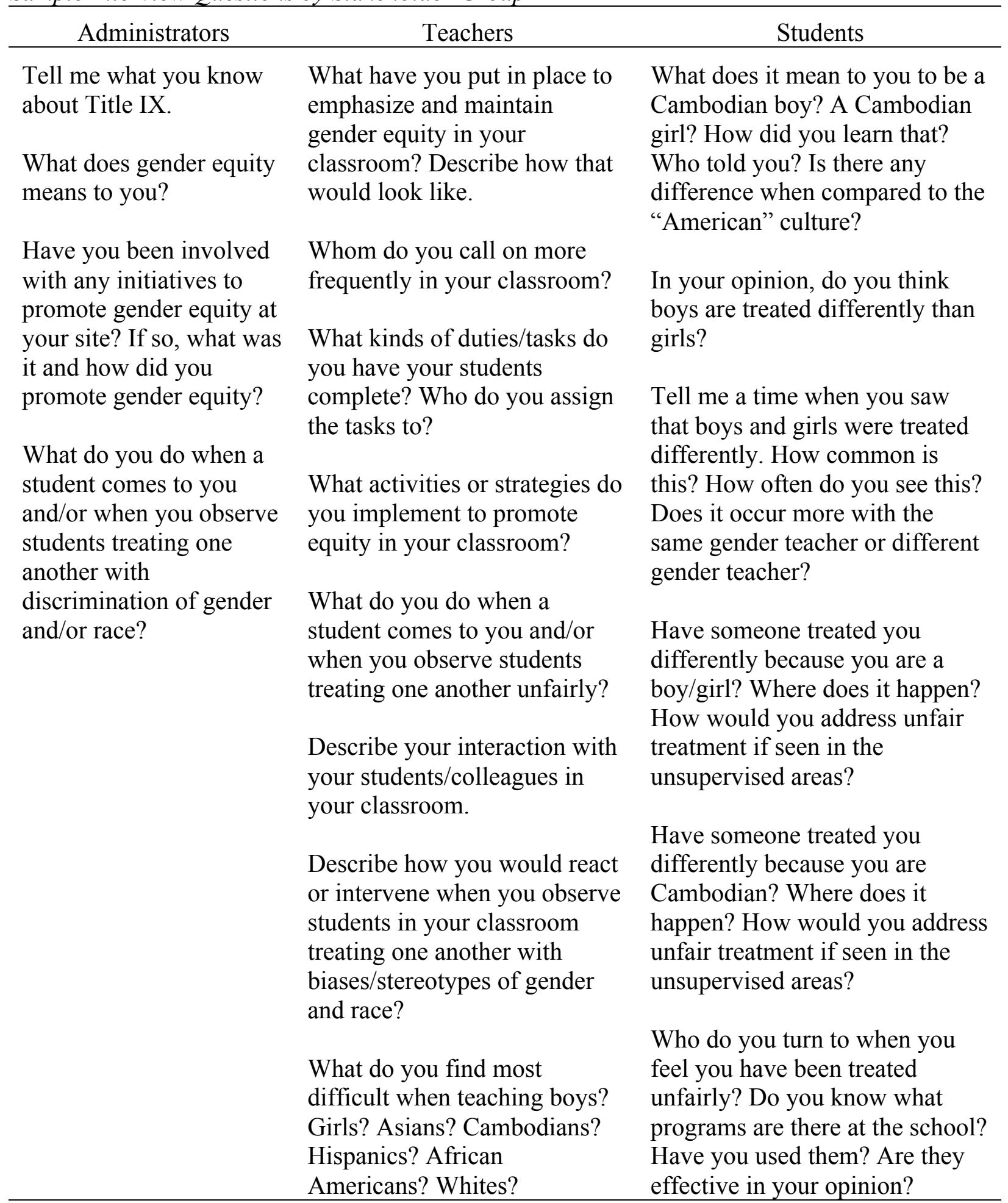


Tang and Kao: Ethnicity, Gender, and the Education of Cambodian American Studen

Tang \& Kao-Ethnicity, Gender, and the Education of Cambodian American Students

\section{Analytical Approach}

A content analysis of the interview transcripts was conducted to identify significant themes and patterns related to our research questions (Patton, 2002). In an iterative manner, the co-authors read and re-read the transcripts individually and met regularly to compare our analyses. First, we read the transcripts to code the data based on broad categories or themes. Examples included the following: teacher to student interaction; school-related curriculum or activities; the students' perceptions of gender; the students' sense of ethnic self-identity; staff perceptions of Cambodian American students; parental expectations; and how all of these issues related to the students' academic experience or achievement. Second, the codes were categorized and assessed for patterns or relationships, looking for similarities and differences between the student and staff perspectives. In some cases, we followed up with a participant via telephone or in-person to gather further information or clarification.

\section{Methodological Limitations}

Given its exploratory nature, the reader should be cautious in attempting to generalize the findings from this study to other schools or ethnic groups. This study sought to provide some insight to the unique issues impacting the Cambodian American youth, whose experiences and perceptions may be different from those of other students. The study took place in an urban high school in Southern California with a high concentration of Cambodian students. A small purposive sample was used to target stakeholders who would be the best informants, but may not be representative of the entire school staff or student population. We also focused our sampling to ninth graders.

The lead author (Tang) is a Cambodian American female, who as a young child, fled Cambodia with her family and eventually settled in the U.S. in the 1980s. Her background and experience may have introduced bias into the data collection, analysis, and interpretation. However, we should note that her background and understanding of Cambodian culture also helped the students to feel more comfortable during the interview. The second author (Kao), a U.S.-born Taiwanese American male, was involved with the data analysis and interpretation; his own experience growing up as an Asian American with immigrant parents should also be noted.

\section{Key Findings and Discussion}

The purpose of this study was to explore the roles that gender and ethnicity play in the academic achievement of Cambodian American high school students, drawing information from the students themselves, their teachers, and school administrators. This section highlights several key themes that arose from the interviews: gender and ethnic congruence between staff and student population, ethnicity in the classroom, ethnicity and peer relationships, parental involvement, and familial expectations.

\section{Gender and Ethnic Congruence Between Staff and Student Population}

The gender distribution of the staff seemed to be representative of the student population. During the 2007-08 school year, there were slightly more female students than male students enrolled at the school; this was also the case across each grade level. According to the district's Research, Planning and Evaluation Department, the school had slightly over 200 staff, including 
administrators, teachers or instructors, and pupil services or classified positions. Among the staff, there were more females than males: $55 \%$ versus $45 \%$, respectively. Six of the ten administrators were males: the two co-principals were both males, while three of the four assistant principals were female. The teaching staff was evenly split across gender, with only a slight majority of teachers being female. The pupil services staff, which includes counselors, clerks, secretaries, etc., was also largely made up of females.

The staff was also ethnically diverse, but they acknowledged that more progress can be made to have a staff that better reflected the student population. The majority of the personnel were White $(68 \%)$, while minorities were represented to a lesser degree: African American $(12 \%)$, Hispanics (12\%), and Asians (6\%). One noticeable gap was the lack of Asians in the administrative and pupil services positions. During the time of the study, the school had only three Cambodian Americans staff, including one teacher (female) and the other two in pupil services. One administrator, Charles, put it best, "minorities are lacking all across the board, but that is nationwide." More importantly, the school was attempting to deal with the challenge of an extremely diverse student population. Based on the staff interviews, the school staff was significantly more diverse than in the past, in terms of both gender and race.

The staff felt that it was important to have an environment conducive to diversity. For example, one teacher, Barbara, stated that 'there's constant teaching and modeling of tolerance and courtesy to everyone, and it is just something that we abide by here because there's so much diversity." The male teacher, David, highlighted the importance of connecting with students: "It is the connections with the students, the relationship one has with the student, and sometimes, it has nothing to do with the person's ability, but whether or not the student can relate and is comfortable with that person." All of the students also reported feeling more comfortable with teachers or staff of the same gender or similar ethnicity.

Related to ethnicity, language communication may be a key barrier between the staff and the students or parents given the limited number of Cambodian and/or Khmer-speaking staff. Both staff and students reported that there was a significant need for more Khmer language speakers and translated materials. At the time of the study, there were only three Khmerspeaking staff members at the school. In addition, very few of the documents were translated into Khmer. Interestingly, all of the students reported that they would prefer to bring the materials in English so they could address their parents' questions (e.g. "That way, I know what I'm giving my parents").

The students were generally appreciative for the diversity of the school, with some referring to the school as a "melting pot" of the different racial groups. Tolerance for difference was a critical issue for the staff, according to one student, William: "The teachers are tough with things like sexual harassment and racism. ... They take it seriously." The students generally felt that the staff was diverse with Hispanic/Latino, African American, and Chinese teachers. Only three of the ten students were even aware of any Cambodian American staff at their school and the others responded with surprise (e.g. "Really? I don't know who they are."). While some students appeared to be indifferent when being informed of these Cambodian personnel, others showed more interest. One female student, Jennifer, shared that she would go to the female Cambodian American teacher for assistance. Interestingly, contrary to statements made by staff, the students were either indifferent or unaware that there were more females than males on staff. Conversely, ethnicity seemed to be an important factor for some of the students. 
Tang and Kao: Ethnicity, Gender, and the Education of Cambodian American Studen

Tang \& Kao-Ethnicity, Gender, and the Education of Cambodian American Students

\section{Ethnicity in the Classroom}

The role of ethnicity emerged as important in several ways. Most notably, the unawareness and misperceptions of the Cambodian ethnicity seemed to have adverse effects on the students' education, as well as their interactions with teachers and other students. It was apparent that the Cambodian culture was not very well understood by the staff and unfortunately, the students were not necessarily in the best position to convey their needs or interests. For example, several students shared that they have been told by their parents to respect their teachers and not to cause any problems. However, to the teachers who were more accustomed to a friendlier teacherstudent relationship, the students appeared to be distant or disconnected.

The Cambodian American students were commonly perceived generically as Asian or mistaken for another Asian ethnicity (e.g. Chinese or Korean). Moreover, according to two teachers, Nancy and David, it was more common for students of other Asian ethnicities to respond when mistakenly referred to as being Cambodian. One of the teachers, Barbara, did not know how many Cambodian American students were in her class:

I know it's sad, but I can't even tell you if the Asian students in my class [are] Khmer or Chinese or Vietnamese. I know that the student is Asian, has an Asian last name, and looks Asian. I know that we have a lot of Khmer students, and the only way I can tell them apart is when the student tells me their ethnicity. Oftentimes, the Khmer students don't tell me that they are Khmer. Other Asian students would tell me. I don't know why.

Another teacher, Linda, shared a similar sentiment:

I don't make any assumption of where students are from. But typically when I mistakenly address students of a specific background, for example, Chinese students, they would correct me and tell me, "No, I'm Chinese." I see very few Cambodian students who'll tell me that they are Cambodians. I see more Chinese, Korean, Japanese and Vietnamese students who'll speak out and say that they are not Cambodians. It is very interesting.

Due to this lack of awareness, it is possible that the teachers were not fully aware of the unique educational needs of their Cambodian students. A number of researchers have argued that the model minority myth has resulted in a common misperception that all Asians are smart and excellent students (Chou \& Feagin, 2008; Kao, 1995; Ng, et al., 2007; K. Yang, 2004). Since the students were commonly mistaken as other Asian ethnicities, their teachers may have had certain academic expectations of them.

According to the staff, Cambodian American students were largely viewed as not being a problem unless they were involved with gang-related activities. In general, the Cambodian students were commonly described as "very obedient," "extremely respectful," or "not a behavioral concern." Some teachers expressed concerns regarding how quiet and passive many of the Cambodian students were. For example, Nancy shared, "They are very quiet, and sometimes they are so quiet that they are almost invisible in the class." Among the staff and teachers, gang involvement also came up as an important concern for the Cambodian boys; however, it was not clear whether these perceptions were based on actual reality or stereotypes (Chhuon, Hudley, et al., 2010). 
Several students shared that they were having trouble with their coursework, which seems to contradict the model minority label. However, because they were fearful of disappointing or bothering their teachers or being embarrassed in front of their peers, they often stayed silent about their needs and did not seek additional assistance. For example, one male student, Michael stated:

Sometimes it's good because teachers will just ignore me and move on to another student. Sometimes, it's not good because teachers don't think that I need help, and it's embarrassing sometimes. For example, when we do group work, the other students in the class would tell the teachers that they want to be in my group because I'm Asian and Asians are supposed to be smart. It's a lot of pressure. I know that I'm not that smart, but I do try really hard. And when I don't do well, they blame me and said, "You're really not Asian, you're just Cambodian."

Similarly, another female student, Mary, shared:

Sometimes the teachers just ignore me when I ask for help. I mean it's rare that I raise my hands and ask for assistance, but when I do, the teacher sometimes would just ignore me. For example, one time, the teacher told me that since I am smart, I can help another student. Little did she know that I was completely lost in that class. I kind of try telling her, but she was too busy I guess. So, I made up some excuses to avoid helping that person, so the teacher gave me [a] lecture about how disappointed she was.

The teachers did notice that many Cambodian American students were not doing well. Nancy expressed that her Cambodian students were neither excelling academically nor being behavioral problems, so they generally went unnoticed:

I do not have any stellar Cambodian students. They're kind of like surfing just below the radar. A lot of them are under the assumption that, "Oh, I'm Asian. I'm smart" and in some of their classes they may be getting away with it like that because they don't cause a problem. They are so quiet that they are often undetected. So, if you have that persona where you can sit in class without being disruptive, teachers will pass you for that particularly if everybody else around you is misbehaving.

Specifically, the teachers found that the Cambodian American students in their English classes, including those born in the U.S., tended to have significant problems with English language structure, grammar, and writing. The teachers did not see this as a problem for students of other ethnicities, as Linda shared, "Even the older first generation, the Chinese, Japanese, Koreans and Vietnamese students learn to speak English fluently, but for some reason, the Cambodians are still having difficulties in these areas." One potential explanation may be the dichotomy between school and home, as another teacher, Barbara, shared:

Many of the Cambodian students if they're first generation American, they're illiterate in Khmer. So the transition from Khmer into English, they find difficult. In their writing they make the same errors, just about, you know. But I do think it's a language difference, particularly in Khmer is the language spoken mainly in the home. There's no carry through. 
Tang and Kao: Ethnicity, Gender, and the Education of Cambodian American Studen

Tang \& Kao-Ethnicity, Gender, and the Education of Cambodian American Students

All four teachers shared that there was a need for more training on how to serve the Cambodian American student population. In addition, English language programs were currently geared to Spanish-speaking students and the teachers felt that it should also address the needs of a growing Asian student population (including Cambodians).

\section{Ethnicity and Peer Relationships}

From the student interviews, it was apparent that the issue of ethnicity also influenced their interactions with their peers. On the surface, the students generally did not view being misidentified as another Asian ethnicity as a significant problem. One female student, Lisa, who reported being mixed Chinese and Cambodian, went on to share that she liked being referred to as Chinese:

I think more people think highly of Chinese students than Cambodians, so I don't mind if the teacher calls me Chinese. People know more about Chinese than Cambodian culture, and people view the Chinese culture and people, especially girls as beautiful, and exotic. When people think of Cambodian, they say, "Where?" or "What's that?" or "What kind of food is that?" People say nothing beautiful about the Cambodian culture or the country or even the people. If they say anything at all, it's about the civil war or Pol Pot and nothing else.

One disturbing finding was that many of the Cambodian American students were marginalized by other students-particularly those of other Asian ethnicities. The students shared that Cambodians were viewed negatively by students of other racial/ethnic groups, based largely on stereotypes (e.g. perceptions of Cambodians as being poor). For example, students of other Asian ethnicities did not like being identified as Cambodians. Michael explained:

...they (students of other Asian ethnicities) are offended when someone thinks that they are Cambodian and they are not. They would say really fast, and in a mad voice, [and] sometimes, they would yell, "Hey, I'm not Cambodian, I'm Chinese or Vietnamese or Japanese" or whatever they are...Koreans especially don't like to be called Cambodians, but more so they hate being called Chinese.

When asked why, the majority of the students did not know while a few students thought it might have to do with ethnic tensions that originated from conflicts in their home countries, e.g. Cambodia and Vietnam. For example, Michael stated:

I think it has a lot to do with war. Back in Cambodia, there were fights among Cambodians and Vietnamese for example. No one liked each other then. One group thinks it's the other's fault for causing the war and killing each other's family. So now, no one wants to be Vietnamese or Cambodian. It's an insult to be the other, and a betrayal if you have friends that are Vietnamese or Cambodian. I still hear my grandparents talk about how the Vietnamese soldiers didn't help the Cambodians when they asked for help during the Vietnam War and Khmer Rouge time. 
Another possible factor may be that other groups perceived Cambodians as being of lower socioeconomic status, according to another male student, John: "As for the Chinese, I think they think that they are all smarter than Cambodians. So, when they are called Cambodians, they don't like that." He further shared:

I hear comments made by Chinese students, and a few of them are my friends. They would poke fun of the other Cambodian students of the way they talk, dress, and sometimes, it gets really personal where they would talk about the types of jobs Cambodians typically have. I guess by the things they say, they think they are better off than Cambodians.

One of the female students, Mary, stated:

Other people don't want to be identified as Cambodians. For example, there's a Vietnamese girl in my class and when the teacher mistook her to be Cambodian, she made a nasty face and said, "No, I'm smarter than them." It hurts, but I try not to let it bother me.

Similarly, another female student, Patty, shared:

This is my second year here in U.S. ...I don't speak that good. I don't know why, but I see Chinese, Korean. I think that's the name, and Vietnamese don't like to be called Khmer. They would tell the teacher "No." I don't think being Khmer is bad, but they think so...Are Khmer people here bad?

As a consequence, it became clear that other students often looked down upon and harassed the Cambodian American students.

Unfortunately, these types of negative peer interactions may have led to the further isolation of the Cambodian American students, discouraging them from engaging in their classes and other school activities. For example, fearful of what their peers might think, some students shared that they would rather receive lower grades for class participation. This sentiment was apparent in the following statements made by a female and male student, respectively:

Jennifer: I remembered the times when I feel that the other students look at me as if I'm from a foreign country. They would speak to me in a slow motion. I would prefer not to speak at all even if it means that I get a lower grade. Besides, I like being the smart one, so why ruin it and get a bad reputation? So, now I just try to be one of the smart one and not ruin it by bringing the attention to myself that I need help. I don't think I'll be going to college anyway.

Michael: Sometimes I just don't ask question so that I can blend in. I prefer not to talk. Because I'm afraid that if I open my mouth, my teachers and peers would know that I'm not Chinese or Korean or Japanese or Vietnamese, you know the smart ones...but this way, because my teachers believed that I'm one of the smart ethnic groups, they don't asked me much questions and they leave me alone. I stay away from trouble, and even though sometimes I know that eventually, the teacher will find out that I actually am having difficulty with my school work, the year has gone and there's really nothing they 
Tang and Kao: Ethnicity, Gender, and the Education of Cambodian American Studen

Tang \& Kao-Ethnicity, Gender, and the Education of Cambodian American Students

can do about it. I'm just used to playing the "smart" one that it's difficult being the "stupid" one, so I just let it be. I don't ask for help so that I can avoid being discovered, does that make any sense?

Statements by the students also suggest the racial discrimination or other racially motivated incidences, including bullying and harassment, were common occurrences - both from students of Asian ethnicity and other races. These experiences seem consistent with previous research on Cambodians and other Southeast Asian groups (Lee, 2001, 2005). While physical confrontations were more common for male students, the female students encountered racial discrimination in the form of verbal attacks. The following are three statements shared by three male students:

Michael: I tried really hard to be friends with the Black group or with the Hispanic groups because they can back me up, you know? [Because] I'm Cambodian, I get into fights with Vietnamese boys. They don't like Cambodians. There's a lot of hatred between the Chinese, Vietnamese and Cambodians. No one wants to be known or called by other race, you know?

William: I don't like staying late after school because that means I have to go home alone. I sometime get beat up because I'm Cambodian... Yeah, they tell me because I'm Cambodian and they don't like Cambodians.

John: The Chinese don't like us Cambodians. They will say things like, "Nah man, I ain't stupid or dark like the Cambodians." Man, we would fight. I'm not proud of it, but you know you gotta defend our kind.

Unfortunately, Cambodian American students were also less likely to report such events, according to the staff and teachers. One female teacher, Linda, explained, "I hear some of my students say that they get beat up...on the way to and from home/school. When I asked them what happen, they don't tell me in detail. I think they don't report them as much as they are actually experiencing it, at least, that's my impression." David, the male teacher, expressed a similar view: "I don't know why they don't complain about the issues to anyone. I have a lot of Latino/Hispanic students complaining of racial discrimination, even though it sometimes doesn't appear to be a race issue, but because they feel that they are discriminated, they will voice it. Not with the Khmer students." Because most students were not reporting these events which mostly occurred outside the school setting, the teachers felt that their ability to address these issues was very limited.

These findings clearly highlight the importance of ethnic identity, which as ninth graders, many of the students were still in the process of developing. Ethnic identity development - or "the degree to which a person feels connected with a racial or cultural group, one's familial ethnic group while growing up" (Bennett, 2001, p. 192) - is a complex cluster of self-labeling, feelings of belonging or isolation, desires to participate in activities and feel accepted within the majority group. In this "equity pedagogy" framework, Bennett argues that students' readiness and comfort with other racial groups is influenced by their satisfaction and healthy sense of ethnic identity. Only then will students feel comfortable to interact in a diverse setting and have higher levels of self-esteem. In contrast, many Cambodian American students, at this age, may be experiencing social and cognitive instability in their identity development (Asher, 2002; 
Hahm, Guterman, \& Lahiff, 2004; Lee, 2001; Lei, 2003). Chhuon and Hudley (2010) argue that a supportive environment may help these students to develop more positive identities.

\section{Parental Involvement}

In terms of parental involvement, the majority of the staff felt that the parents of their Cambodian students were either unaware of or simply did not question the school and staff expectations and policies. Furthermore, it was a common perception among the majority of the staff that the parents typically did not get involved in their child's education. For example, few Cambodian parents would attend the school's open house, back-to-school events, parent conferences, or any other activities, even when students were given incentives to bring their parents (such as extra credit). Several staff felt that the lack of transportation or work obligations were potential reasons. Even when the parents attended a school event, one female teacher shared:

Nancy: ...the parents are so quiet. It is as they were not physically present. I mean they don't show any interest in what was discussed, no facial reaction of good or bad, very indifferent. When the students point out their work sample, the parents typically have no expression, and no comments were made. I mean these are parents who have been in the States for a while, they are second or third generation, so they do speak English. They don't ask any questions, just smile and as soon as the information about the class was shared, they disappear for the rest of the night.

The students also acknowledged that their parents were not involved in their education and raised several explanations. According to some students, language or cultural barriers played an important role:

Lisa: My parents don't see the point in them coming to my open house or Back-to-School night. I guess they had a bad experience when they came that one time. The teacher didn't talk to my parents. They just sat there, pretending to listen and when it was time to leave, they left. I tried to translate to my parents what's going on, but I wasn't allowed to talk when my teachers were talking.

Robert: [My parents] felt it was a waste of time. My parents explained to me one time that they will only go to one school activity. When I asked them why, they told me that they didn't liked to be lectured to. My dad said that all the teachers do is lecture them about how bad their child is doing in class, and he felt that they were saying how bad they were as parents in so many words. They felt that they talked down [to].

Patty: My parents would also ask me, what for? They don't understand why it is even necessary, especially when no one speaks their language.

Other students shared that their parents were too tired and busy working to participate in school activities or that it was difficult to bring the entire family using public transportation. It was difficult to gauge how the students felt about their parents' lack of involvement in their education. A previous study found that Cambodian American college students perceived the lack 
Tang and Kao: Ethnicity, Gender, and the Education of Cambodian American Studen

Tang \& Kao-Ethnicity, Gender, and the Education of Cambodian American Students

of parental informal education to be significant barriers because they were not getting any help at home with their school work (Chhuon, Hudley, et al., 2010).

\section{Familial Expectations}

In regards to gender roles and family expectations, the students were clearly struggling with conflict between the school and home settings. For most of the students, their academic aspirations were trumped by their roles at home. For example, the students were often absent from school to attend to familial responsibilities. As several students shared, they were unable to participate in many activities or were often absent because they had to take care of a family member or work to earn money for the family. A male and a female student made the following statements, respectively:

John: My parents says so and so doesn't have a high school diploma and he's doing pretty well for himself, see? Then my mom would say that they don't know any Cambodians who's rich and makes it big. If anything, they wasted their money in the long run going to college. But I'm going to try anyway.

Mary: My dad didn't want me to go to college. He says that I should go to the community college first to save money, and if I'm lucky, hopefully, I'll be married off to a rich guy who has a business of his own. If that's the case, I won't be going to college. Beside, my dad told me that boys should go to college so that they can provide more for their family.

All of the students expressed that their parents understood the importance of a high school education, but the responses were more mixed when the discussion turned to a college education. All of the students reported at one time or another they were discouraged from going to college.

These findings highlight the importance of familism (i.e. family duties and obligations), which is common across Cambodian and many other Asian cultures (Pho \& Mulvey, 2007; Segal, 2002). Another prominent feature is the preferential treatment of sons over daughters (A. Ong, 2003; Pho \& Mulvey, 2007). It was apparent that gender and gender expectations had a varying impact on the education of the Cambodian boys versus girls. On one hand, the expectations for Cambodian boys were to support the family, but a college education was still a viable alternative for some boys. On the other hand, Cambodian girls were expected to get married and take care of the family, which made it more difficult to pursue their current and future educational goals. This finding is similar to previous studies. For example, in their study of Southeast Asian women in Lowell, Massachusetts, Pho \& Mulvey (2007) also found that boys (particularly the oldest child) were encouraged to earn an education while the girls were being prepared for the next stage, that is, "to be a the wife of another man and the daughter-in-law of another family" (p. 186).

While the staff had a general sense that these families were experiencing financial difficulties, the teachers also questioned why the students were not placing more importance on their coursework. Because of these difficulties, Cambodian students were often absent-and possibly more frequently than students of other ethnicities. This problem was highlighted by a bilingual school-community worker (Christopher) who participated in the informal interviews: 
Among the Asian group, the Cambodian students have the most attendance problems, and it's not due to illness. There [are] a lot of them on this boat and I'm talking about the good kids...the ones who have a great chance [of] succeeding and making something out of themselves. These are the kids I feel bad for because they are missing out on their education to help out their families. That isn't right...but at the same time, they feel obligated to help...I mean, who wouldn't. It's understandable, but it's not fair for these kids.

Another staff person named Elizabeth (an attendance clerk for five years) shared that it is common that the students would report that they "were out because they had to take care of their younger siblings, ill parents/grandparents, or help with family business." Similarly, all of the students reported that they were discouraged from missing school due to an illness but would do so for family obligations. As one male student, James, shared, "my first priority as a child is to always help my family, no matter what." According to the students, the primary reasons for being absent included the following: baby-sitting their younger siblings to save money; working for their family business; acting as an interpreter for their parents; and working part-time.

While the students were able to recognize the differences in gender role expectations, it was not clear whether they viewed these roles as necessarily wrong or inequitable. For the most part, the students seemed to be indifferent. One potential explanation may be that the students have simply accepted their roles because they saw their parents and relatives fulfilling similar roles. Since all of their parents were first-generation Cambodians, traditional values may still be a significant influence in determining one's role in the family and community. The girls were repeatedly reminded of their duty to the family:

Patty: When I tell my mom and dad that my brothers not doing anything, my parents just ignore me and sometimes, they would tell me that I should just let them be, you know, let them continue to do nothing. My parents would tell me that that's what girls are for, to help out with the family, you know.

Susan: My older sister told me that I'm supposed to help my mom take care of my younger sister and brother. My grandmother told me how to be a girl so that I can take care of my family and husband when I'm older.

The male students also saw their fathers, uncles, and other brothers working and providing for the family and thus, expected to do the same:

James: I learn it from my older brother. He taught me a lot on how to be a man. I must watch over my little brother. I must protect him and take care of the family. When I am old enough, I can work full time. Right now, after school, I must go and work so that I can help bringing in some money. You can't take care of the family if you don't bring in the money.

John: I learned it from my dad and by watching TV when I was younger. I watch what my dad watches, and do what he does. He tells me that boys can do certain jobs like playing sports and architect and make lots of money. 
Tang and Kao: Ethnicity, Gender, and the Education of Cambodian American Studen

Tang \& Kao-Ethnicity, Gender, and the Education of Cambodian American Students

The students' acceptance of their role expectations seems consistent with existing literature (Dinh, Weinsteain, Kim, \& Ho, 2008; Zhou, 1997, 2001). For example, a study by Dinh et al. (2008) showed that Cambodian American students tended to adopt a "bicultural mode of acculturation," in which they developed competence in traversing between two distinct cultures - one that is clearly delineated between school and home. The students may have also adopted this bicultural orientation as a necessity to cope with the often-competing expectations in and out of the home. Then again, it is also possible that the students - since they were only in the ninth grade - were still developing their own identities and in that process, may become more conflicted in the future.

\section{Concluding Remarks}

The purpose of this study was to explore the potential role that gender and ethnicity may play in the academic experience of Cambodian American students in a large urban high school, using the perspectives of the students themselves, their teachers, and the school administrators. The findings emerging from this study may help to further our understanding regarding the experience of Cambodian American students in our educational system and how issues, such as gender and ethnic identity, can affect their academic achievement.

The findings from this study suggest that the youth were conflicted between what was expected of them at home (by their parents) versus the expectations at school (by their teachers and peers). This tension seemed to have a profound impact on their educational aspirations; however, the impact varied across gender. For example, despite familial obligations, education seemed to be more encouraged or supported for the boys and college was still a viable option. In contrast, the expectations for girls were more focused on familial duties and responsibilities. Still, many of the girls we interviewed intended to continue in their education, including going to college. Based on their study of Southeast Asian women in Lowell, Massachusetts, Pho \& Mulvey (2007) argued that economic necessity has led to an altering of the family structure, where increasingly more women are working to support the family. In addition, since many men were killed during the Khmer Rouge, more women are being forced to be the head of household and the primary breadwinner. Moreover, Chhuon, Kyratzis, and Hudley (2010) argued that the notion of "culture" isn't static. In their study, they found that Cambodian American female college students were able to reframe their family obligations in a way that included personal independence and a successful career.

The impact of familial obligations could be further complicated by the family's particular socioeconomic situation. Regardless of gender, both boys and girls seemed to face pressures to help to support the family financially. Therefore, while the parents may stress the importance of a formal education, the educational attainment of their own children was somehow moderated by the family's socioeconomic situation. This finding seems consistent with previous research. For example, Dinh et al. (2008) found that a Cambodian cultural orientation predicted a stronger belief in the value of education while an Anglo/White cultural orientation predicted both higher grade point averages and educational aspirations. One possible interpretation may be that Cambodians do value education, contrary to what many educators may believe. However, many of these families face tremendous socioeconomic challenges and this reality may force them to choose between their immediate financial needs and the long-term educational needs of their children. Future research could focus on the potential moderating effects of gender and/or socioeconomic status on the education of Cambodian American students. 
This study also showed that the school was struggling to address the specific academic and social needs of its large Cambodian American students. For example, the findings suggest that the Cambodian American students were a marginalized group in the school, due to either the stereotyping or misunderstandings of both the educators and other students, which in turn, may be impacting their educational experience. Therefore, more work is needed to address the academic and social needs of the Cambodian American student population. For one, school administrators - along with the district-could develop a strategy to recruit and hire more Cambodian American staff, particularly teachers. Despite Cambodian Americans representing one of the largest minority groups at the school, only three members of the school's staff were Cambodian (including just one teacher).

A more culturally competent staff may also help to engage the parents of Cambodian American students in their children's education. Unfortunately, the lack of parental involvement was often perceived by the teachers as a lack of interest or engagement in the child's education. In general, we found that parental involvement in their child's academic activities was minimal but there may also be practical reasons, e.g. the parents are simply too busy either working or taking care of the family. Another possible explanation not explored in this study is the Buddhist belief of "destiny" which tends to contradict the American values of personal effort in one's education. Based on this belief, Cambodian parents tend to take on a more "laissez-faire approach to their children's education," which is commonly misinterpreted by educators as not valuing education (Ngo \& Lee, 2007). In addition, the strong explanatory power of structural factors, such as parental own socioeconomic or educational background, on the educational achievement of their Cambodian children cannot be ignored (Kim, 2002).

The school could also promote greater awareness and cultural sensitivity of the Cambodian American population among its teachers and other personnel, as well as the broader student population. This, in turn, may impact their educational experience and overall educational attainment. Cultural sensitivity trainings and adoption of culturally competent teaching pedagogy could help teachers to work more effectively with the students. Teachers could also collaborate with students from the school's Cambodian student groups to develop school activities that would raise awareness around Cambodian culture. In addition, administrators and teachers could collaborate with the local community organizations or local businesses serving the Cambodian community to develop strategies in working with the students. Community leaders or service providers could also be consulted to provide in-service trainings for the school staff.

The curriculum should also be revised so that aspects of Cambodian history and culture are incorporated in the students' academic experience. Although the students did not express this as a major concern, several teachers shared that there was a lack of literature specific to the Cambodian culture or experience. At the time of the study, there was virtually no literature about Cambodian Americans or by Cambodian American authors-despite efforts to develop a multicultural and inclusive curriculum. School administrators and teachers could consult with local university faculty with expertise in Asian American or Southeast Asian studies.

In order to better address the needs of the Cambodian American students as well as other students, the school should also develop processes to monitor differences in academic achievement for distinct subgroups within its student population. At the time of the study, disaggregated data on specific Asian subgroups were not being collected by the school. Such information could help to draw attention to the struggles of the Cambodian American students, as well as to inform possible interventions. 
We should note that at the time of the study, the school and its staff were working on ways to better address the unique needs of the Cambodian student population. All of the staff interviewed for this study demonstrated the best intentions. In many cases, both administrators and teachers seemed to be committed to addressing the inequities they observed. At the same time, it was not always clear what can be done, especially given limited staffing and financial resources. Their frustration became noticeable at times during the interviews. More resources from the state and federal governments are clearly needed to address the education of our most disadvantaged populations.

This study also demonstrates the tremendous need for further research on the education of Cambodian Americans. While there is increasing awareness of Cambodian Americans as a disadvantaged group, much of the research continues to treat Asian Americans as an homogeneous population. On a national level, many of the Asian subgroups are still relatively small and consequently, there may be a lack of adequate data to allow for statistical analysis. Since Cambodian Americans are mostly concentrated in local regions throughout the U.S., there is a critical need for regional or more localized studies (e.g. at the district or school levels). However, it is important to note that some researchers may have a difficult time gaining entry into this population, especially given the distrust and fear that still exists among many Cambodian Americans (Chhim, 2003). Because the lead author is a Cambodian American female, we felt that we were able to address some of these challenges and more readily gain the trust of the students and their parents.

This paper focused on the role of gender and ethnicity on the education of Cambodian American youth - a population that is virtually "invisible" in the educational system. In doing so, we uncovered both the vulnerability and resilience of a newly emerging group, as well as the well-intended efforts of school administrators and teachers faced with a formidable challenge. Although this study is focused on a single school, the issues and challenges associated with increased diversity are not unique to this district but touch every district and school. Educators have a mandate to ensure that all students have access to the same academic and social opportunities, regardless of their gender and ethnic background. With growing numbers of children from immigrant families, schools have to contend with populations that may not value education in the same way or face socioeconomic forces that make education less of a priority. A better understanding of the Cambodian American experience-through improved cultural competence and awareness - can assist in engaging both the students and their parents. In this way, school administrators and teachers - with the support of the community and parents - could play an important role in ensuring that Cambodian American and other immigrant youth have access to the same opportunities as other students.

\section{References}

Asher, N. (2002). Class acts: Indian American high school students negotiate professional and ethnic identities. Journal of Urban Education, 37(2), 267-295.

Asian American Justice Center \& Asian Pacific American Legal Center. (2006). A community of contrasts: Asian Americans and Pacific Islanders in the United States demographic profile. Los Angeles, CA: Asian American Justice Center.

Asian Pacific American Legal Center. (2004). The diverse face of Asian and Pacific Islanders in Los Angeles County: Asian \& Pacific Islander demographic profile. Los Angeles: Asian Pacific American Legal Center. 
Bennett, C. (2001). Genres of research in multicultural education. Review of Educational Research, 7(12), 171-217.

Chhim, P. (2003). Cambodian Americans. In D. Arguelles (Ed.), The new face of Asian Pacific America: Numbers, diversity, and change in the 21st century (pp. 93-96). Berkeley, CA: AsianWeek \& UCLA Asian American Studies Center Press.

Chhuon, V., Dosalmas, A., \& Rinthapol, N. (2010). Factors supporting academic engagement among Cambodian American high school youth. Journal of Southeast Asian American Education \& Advancement, 5, 1-14.

Chhuon, V., \& Hudley, C. (2010). Asian American ethnic options: How Cambodian students negotiate ethnic identities in a U.S. urban school. Anthropology \& Education Quarterly, 41(4), 341-359.

Chhuon, V., Hudley, C., Brenner, M. E., \& Macias, R. (2010). The multiple worlds of successful Cambodian American students. Urban Education, 45(1), 30-57.

Chhuon, V., Kyratzis, A., \& Hudley, C. (2010). Sources of coherence in the life stories of Cambodian American women at the university. Journal of Language, Identity \& Education, 9(5), 347-362.

Chou, R. S., \& Feagin, J. R. (2008). The myth of the model minority: Asian Americans facing racism. Boulder, CO: Paradigm Publishers.

Dinh, K. T., Weinstein, T. L., Kim, S. Y., \& Ho, I. K. (2008). Acculturative and psychological predictors of academic-related outcomes among Cambodian American high school students. Journal of Southeast Asian American Education \& Advancement, 3, 1-25.

Hahm, H. C., Guterman, N. B., \& Lahiff, M. (2004). Asian American adolescents' acculturation, binge drinking, and alcohol- and tobacco-using peers. Journal of Community Psychology, 32(3), 295-308.

Kao, G. (1995). Asian Americans as model minorities? A look at their academic performance. American Journal of Education, 103(2), 121-159.

Kim, R. (2002). Ethnic differences in academic achievement between Vietnamese and Cambodian children: Cultural and structural explanations. The Sociological Quarterly, 43(2), 213-235.

Lee, S. J. (2001). More than "model minorities" or delinquents": A look at Hmong American high school students. Harvard Educational Review, 71(3), 505-528.

Lee, S. J. (2005). Up against whiteness: Race, school, and immigrant youth. New York: Teachers College Press.

Lei, J. L. (2003). (Un)necessary toughness? Those "loud black girls" and those "quiet Asian boys." Anthropology \& Education Quarterly, 34(2), 158-181.

Ng, J. C., Lee, S. S., \& Pak, Y. K. (2007). Contesting the model minority and perpetual foreigner stereotypes: A critical review of literature on Asian Americans in education. Review of Research in Education, 31(1), 95-130.

Ngo, B., \& Lee, S. J. (2007). Complicating the image of model minority success: A review of Southeast Asian American education. Review of Educational Research, 77(4), 415-453.

Ogbu, J. U., \& Simons, H. D. (1998). Voluntary and involuntary minorities: A culturalecological theory of school performance with some implications for education. Anthropology \& Education Quarterly, 29(2), 155-188.

Olsen, L. (1997). An invisible crisis: The educational needs of Asian Pacific American youth. New York: Asian Americans \& Pacific Islanders in Philanthropy. 
Ong, A. (2003). Buddha is hiding: Refugees, citizenship, the new America. Berkeley and Los Angeles, CA: Unviersity of California Press.

Ong, P. M., \& Leung, L.-S. (2003). Diversified growth. In D. Arguelles (Ed.), The new face of Asian Pacific America: Numbers, diversity, and change in the 21st Century (pp. 7-16). Berkeley, CA: Asian Week \& UCLA Asian American Studies Center Press.

Park, C. C. (2000). Learning style preferences of Southeast Asian students. Urban Education, 35(3), 245-268.

Patton, M. Q. (2002). Qualitative research and evaluation methods. Thousand Oaks, CA: Sage Publications.

Pho, T.-L., \& Mulvey, A. (2007). Southeast Asian women in Lowell: Family relations, gender roles, and community concerns. In J. V. Gatewood (Ed.), Contemporary Asian America: A multidisciplinary reader (2nd ed., pp. 181-205). New York: New York University Press.

Portes, A., \& Rumbaut, R. G. (1996). Immigrant America: A portrait (2nd ed.). Berkeley, CA: University of California Press.

Reyes, A. (2007). Language, identity, and stereotype among Southeast Asian American youth: The other Asian. Mahwah, NJ: Lawrence Erlbaum.

Segal, U. A. (2002). A framework for immigration: Asians in the United States. New York: Columbia University Press.

Smith-Hefner, N. J. (1993). Education, gender, and generational conflict among Khmer refugees. Anthropology \& Education Quarterly, 24(2), 135-158.

Takaki, R. (1998). Strangers from a different shore: A history of Asian Americans (updated and revised ed.). Boston, MA: Back Bay Books.

United States Census Bureau. (2010). 2010 census summary file 1. Washington, DC: U.S. Census Bureau.

Yang, K. (2004). Southeast Asian American children: Not the "model minority." Future of Children, 14(2), 127-133.

Yang, P. Q. (2004). Generational differences in educational attainment among Asian Americans. Journal of Asian American Studies, 7(1), 51-71.

Zhou, M. (1997). Growing up American: The challenge confronting immigrant children and children of immigrants. Annual Review of Sociology, 23, 63-95.

Zhou, M. (2001). Straddling different worlds: The acculturation of Vietnamese refugee children. In A. Portes (Ed.), Ethnicities: Children of immigrants in America. Berkeley, CA: University of California Press. 


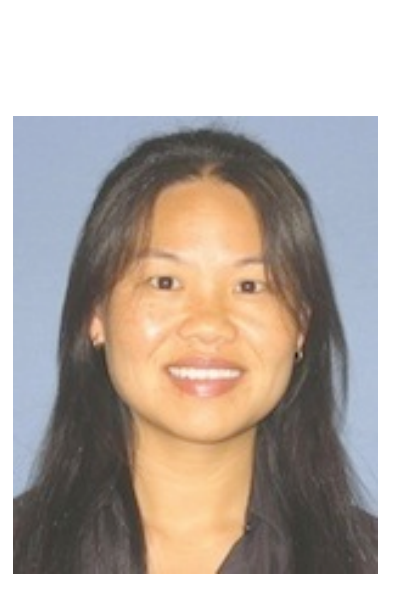

\begin{abstract}
About the Authors
Kimmie Tang is an Instructional Faculty member with the LoneStar LEND (Leadership Education in Neurodevelopmental and Related Disabilities) program at the Children's Learning Institute in the University of Texas Health Science Center at Houston. She also currently works as an independent special education consultant, with over 15 years of experience in the special education field - as a teacher, administrator, and college faculty. Dr. Tang completed her MA in Special Education from California State University at Dominguez Hills and EdD in K-12 Leadership in Urban School Settings from the University of Southern California.
\end{abstract}

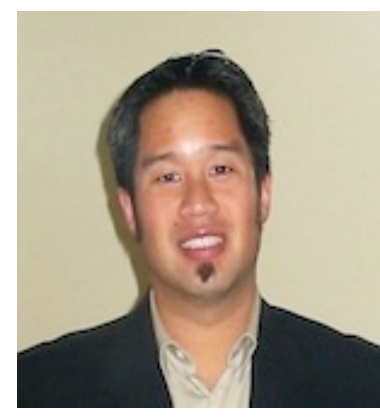

Dennis Kao is currently an Assistant Professor at the University of Houston's Graduate College of Social Work, where he teaches social policy and conducts research on the health and well-being of minority populations. He received his MSW from the University of California at Los Angeles and PhD in social work from the University of Southern California. 


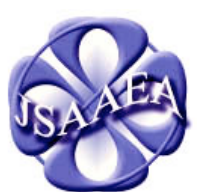

Volume 7 (2012)

\section{Journal of Southeast Asian American Education \& Advancement}

\author{
WWW.JSAAEA.org
}

\section{Editor}

Dr. Wayne E. Wright

University of Texas, San Antonio

\author{
Associate Editors \\ Dr. Chhany Sak-Humphry \\ University of Hawaii at Manoa
}

Dr. Phitsamay Sychitkokhong Uy

University of Massachusetts, Lowell

\section{Book Review Editor}

Dr. Vichet Chhuon

University of Minnesota

\section{Creative Works Editor \\ Bryan Thao Worra \\ Lao Assistance Center}

Special Advisor

Gregory Green

Curator, Echols Collection on Southeast Asia, Cornell University Library

\section{Journal Manager}

Sovicheth Boun

University of Texas, San Antonio
A peer-reviewed scholarly journal published by the

National Association

for the Education \&

Advancement of

Cambodian, Laotian,

and Vietnamese

Americans (NAFEA)

Comments and questions for the editorial staff may be directed to jsaaea@1ists.sis.utsa.edu

\section{Editorial Review Board}

\author{
Dr. Steve Arounsack \\ California State University, Stanislaus \\ Dr. Phala Chea \\ Lowell Public Schools \\ Dr. Loan Dao \\ Cancer Prevention Institute of California \\ Dr. Changming Duan \\ University of Missouri, Kansas City \\ Dr. Jeremy Hein \\ University of Wisconsin - Eau Claire \\ Dr. Samlong Inthaly \\ Minneapolis Public Schools \\ Dr. Kevin K. Kumashiro \\ University of Illinois, Chicago
}

Dr. Carl L. Bankston III

Tulane University

Dr. George Chigas

University of Massachusetts, Lowell

Dr. Hien Duc Do

San Jose State University

Dr. Sophal Ear

U.S. Naval Postgraduate School

Dr. Nancy H. Hornberger

University of Pennsylvania

Dr. Peter Nien-Chu Kiang

University of Massachusetts, Boston

Dr. Ha Lam

Arizona State University 

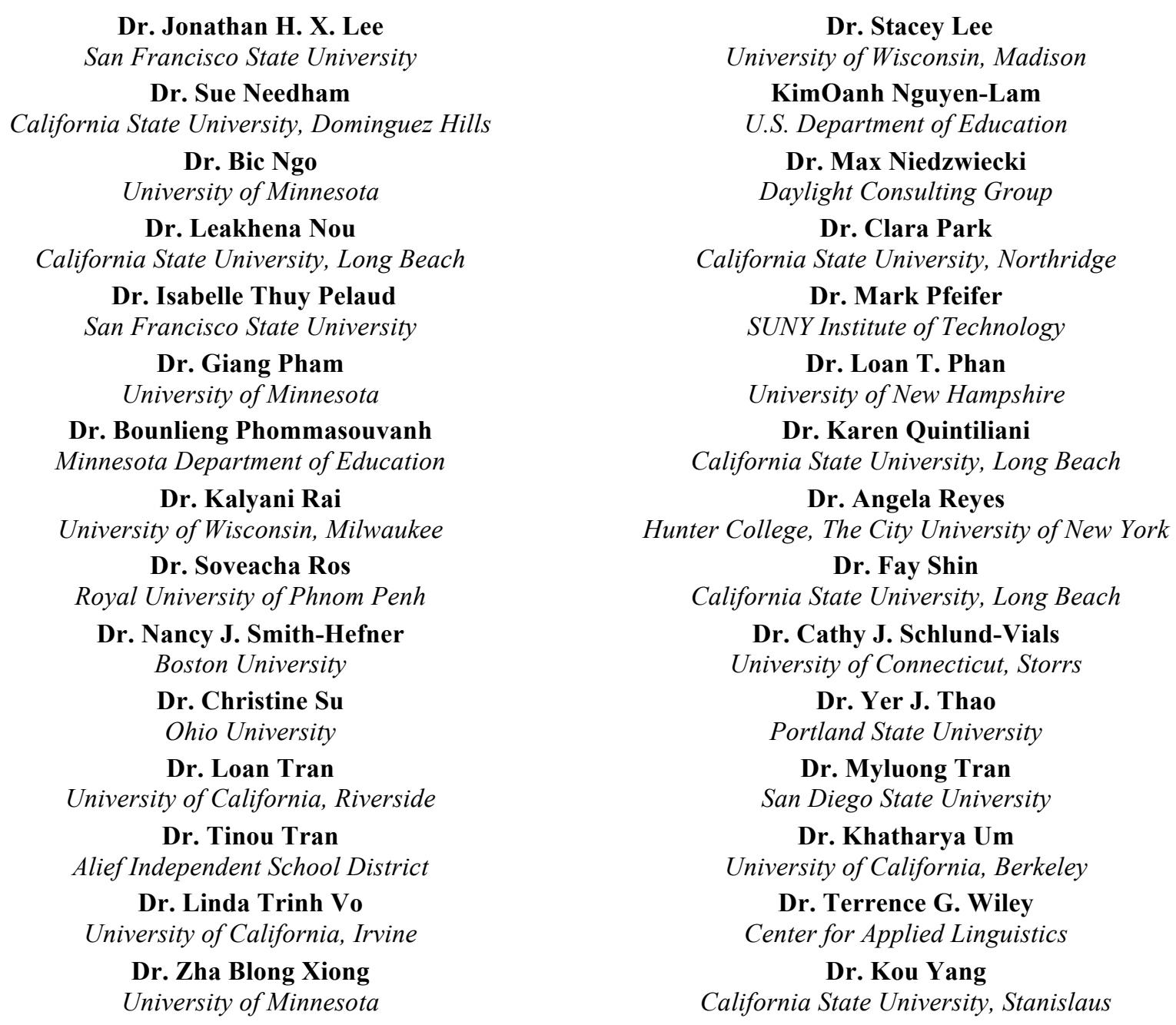

\section{Doctoral Student Editorial Review Board}

\author{
Keo Chea-Young \\ University of Pennsylvania \\ Ketmani Kouanchao \\ California State University, Fullerton \\ Ravy Lao \\ University of California, Santa Barbara \\ Thien-Huong Ninh \\ University of Southern California \\ Vanna Som \\ Harvard University \\ Krissyvan Truong \\ Claremount Graduate University \\ Yang Sao Xiong \\ University of California, Los Angeles
}

\author{
Annie BichLoan Duong \\ San Joaquin County Office of Education \\ Peter Tan Keo \\ Columbia University \\ Monirith Ly \\ Texas State University-San Marcos \\ Malaphone Phommasa \\ University of California, Santa Barbara \\ Alisia Tran \\ University of Minnesota \\ Silvy Un \\ University of Minnesota \\ Yeng Yang \\ University of Texas, San Antonio
}

